\title{
AN IMPROVED CURRENT CONTROL SCHEME FOR THREE-PHASE SHUNT ACTIVE POWER FILTERS TO OVERCOME POWER QUALITY ISSUES
}

\author{
Abeena A \\ Department of EEE \\ NSS College of Engineering \\ Palakkad, Kerala, India \\ Asmabi V \\ Department of ECE \\ $\mathrm{Al}$ Ameen Engineering College \\ Palakkad, Kerala, India
}

\author{
Ajeena A \\ Department of ECE \\ Al Ameen Engineering College \\ Palakkad, Kerala, India \\ Saneep K \\ Department of EEE \\ NSS College of Engineering \\ Palakkad, Kerala, India
}

\begin{abstract}
The paper proposes an advanced current control strategy to enhance the performance of shunt Active Power Filter(APF) with the aid of PI-VPI controllers in order to achieve harmonic current compensation and to overcome the various power quality issues that exists in power system. The proposed control scheme requires only two current sensors and does not need a harmonic detector. The absence of harmonic detector not only simplifies the control scheme but also improves accuracy of the APF. Furthermore, the total cost to implement the proposed APF becomes lower, owing to the minimized current sensors and the use of a four-switch three-phase inverter.
\end{abstract}

Keywords - Four-switch three-phase inverter (FSTPI), harmonic current compensation, PI-VPI current controller, power quality, Shunt active power filters (APFs).

\section{INTRODUCTION}

The increasing use of nonlinear loads such as adjustable speed drives, electric arc welders, and switching power supplies causes large amounts of harmonic currents inject into distribution systems. These harmonic currents are responsible for voltage distortion, increasing power losses and heat on networks and transformers, and causing operational failure of electronic equipment [1], [2]. LC passive filters are traditionally utilized to compensate the harmonic currents since they are simple and low-cost solution. However, they are often large and heavy. They potentially cause undesired resonance problems [3]. Shunt APFs are recognized as a flexible solution for harmonic current compensation since they are capable of compensating harmonic currents generated by many types of nonlinear loads as well as providing fast responses to load variations. The purpose of an APF is to generate harmonic currents having the same magnitude and opposite phase with the harmonics produced by the nonlinear load, and to ensure that the supply currents contain only the fundamental component [4], [5].

The APF must generate the harmonic currents to compensate harmonics produced by the nonlinear load and to make the supply currents sinusoidal. To fulfill these demands, the traditional control scheme requires a harmonic detector and current controller where both loops must be designed properly to achieve good control performance. However, it may cause excessive complexity in the design process [4], [5]-[7]. The harmonic detector aims to extract the harmonic components presented in the load currents whose output becomes the reference filter current for the APF. Thus, the performance of this process critically impacts on the accuracy of the APF. The harmonic detector is typically employed by using filters such as high-pass, low-pass, adaptive filters or through complex mathematical functions. However, by using these filters, it is difficult to achieve both fast response and good steady-state harmonic tracking performance [5]-[10].

In the proposed control scheme, the supply currents are directly measured and regulated to be sinusoidal by an effective harmonic compensator, which is developed based on a PI and VPI controllers and implemented in the fundamental reference frame [11]. Owing to the effectiveness of the proposed PI-VPI controller, the harmonic currents produced by the nonlinear load can be accurately compensated without the demand of a load current measurement and harmonic detector. The absence of the harmonic detector not only simplifies the control scheme but also significantly improves 
the accuracy of the APF since the control performance is no longer affected by the performance of the harmonic tracking process. Moreover, the total cost to implement the proposed APF is lower, owing to the minimized current sensors and the use of a four-switch three-phase inverter (FSTPI).

\section{SCHEME Using In PROPOSED CONTROL STRATEGY TO IMPROVE APF PERFORMANCE}

In order to improve the performance of shunt APF the proposed strategy is mainly using PI plus VPI current controllers.

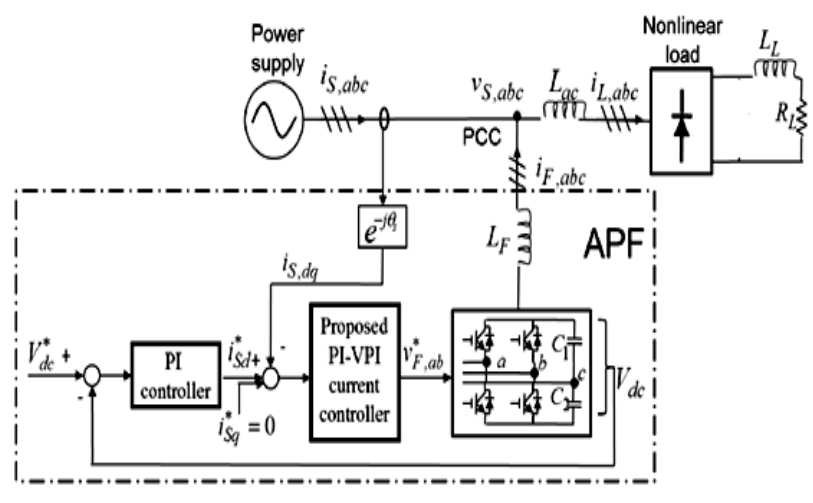

Fig. 1. Block diagram of proposed system with APF

\section{A. Structure of Shunt APF}

In the attempt to minimize the harmonic distortion from nonlinear loads, the choice of active power filters (APFs) emerges to improve the filtering efficiency and solve the issues of classical passive filters. Shunt APFs are recognized as a flexible solution for harmonic current compensation since they are capable of compensating harmonic currents generated by many types of nonlinear loads as well as providing fast responses to load variations. A shunt APF is basically a three phase voltage source inverter (VSI) connected in parallel with a nonlinear load at the point of common coupling through an inductor $L f$. The energy storage of the APF is a large capacitor located at the dc-link side of the inverter. The nonlinear load can be presented as a RL load connected to the power supply through a three-phase diode rectifier. Since the APF must generate non-sinusoidal currents, the design of the current controller for the APF is a challenging task. As stated earlier, the APF must generate the harmonic currents to compensate harmonics produced by the nonlinear load and to make the supply currents sinusoidal.

\section{B. Proposed Current Controller}

The proposed control strategy uses PI plus VPI current controllers in their fundamental reference frame. The supply current is directly sensed, and the current controller is executed to regulate the supply current to be sinusoidal. A conventional PI controller employed in the fundamental reference frame is sufficient for regulating the sinusoidal signals since these signals behave as dc signals in this frame[12]-[15].

However, in the APF system, it is impossible to force the supply currents to be sinusoidal by using only a PI controller because the supply currents are not directly but indirectly controlled by regulating the filter currents which are the non-sinusoidal signals. In fact, due to the limitation of the control bandwidth, the PI controller is unable to adequately regulate the high frequency signals, e.g., harmonic currents. As a result, the desired control target of the APF cannot be achieved by using only PI current controller [16].

The proposed PI-VPI controller is capable of preventing this problem. The use of VPI controllers significantly improves the stability margin and accuracy of the proposed current controller. The complete proposed current control scheme using the PI-VPI controller is shown in Fig. 1. Since the proposed current controller is designed in the fundamental reference frame, the measured supply current must be transformed from the stationary to the fundamental reference frame. The proposed current controller is then executed to regulate this current follow its reference. The outputs of the current controllers and the feed forward supply voltage term are added together and then transformed in the stationary reference frame through an inverse rotational transformation to obtain the command voltage, which is the control signal for the APF.

\section{Description Of The Whole Control Strategy}

The proposed control scheme contains two main loops: the dclink voltage control and the supply current control. In addition, since the proposed current controller is employed in the fundamental reference frame, a phase-locked loop (PLL) is required to track the phase of the supply voltage, which is needed, for coordinate transformation and synchronization. 


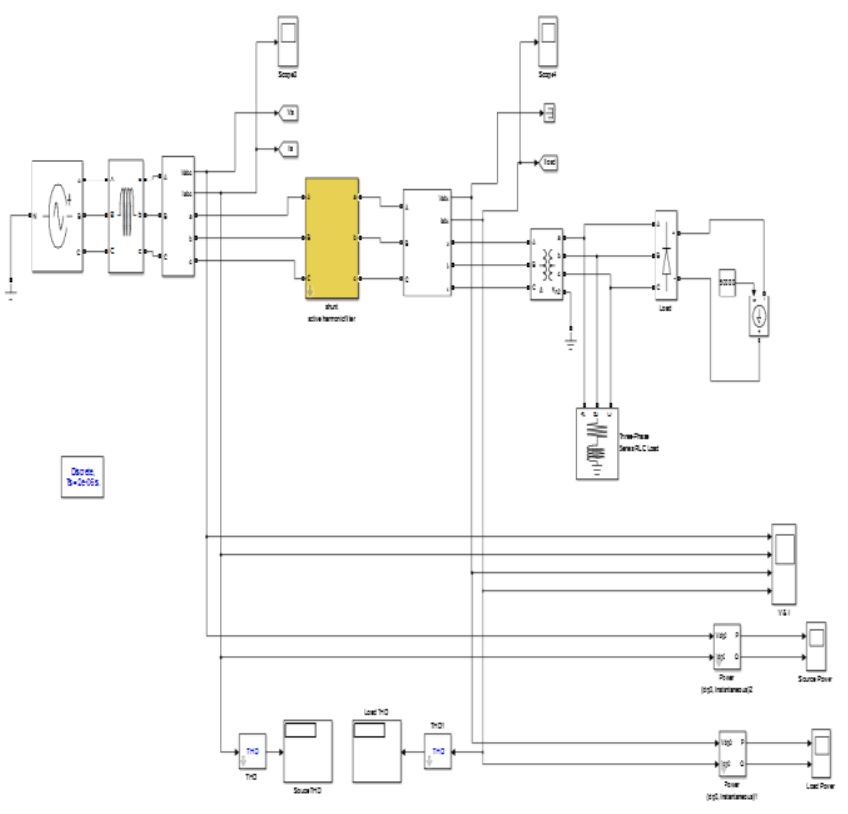

Fig. 2. Simulated system

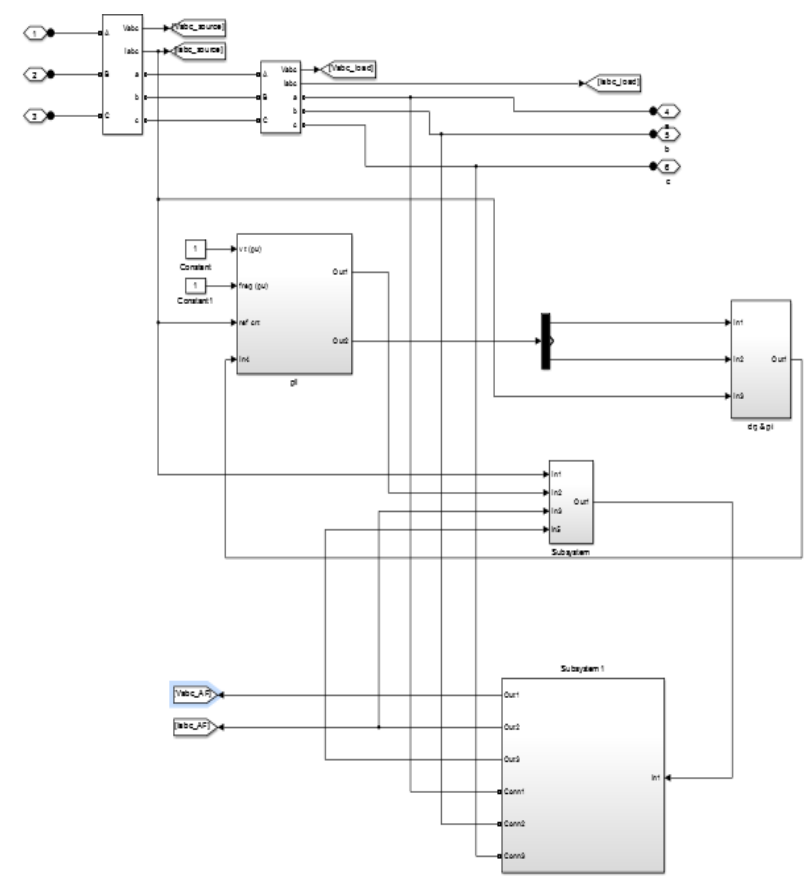

Fig. 3. Simulation of Subsystem with PI-VPI Controller

\section{A. DC-Link outer Voltage Control Loop}

This control loop aims to keep dc-link voltage of the shunt APF constant through a simple PI regulator, whose output is the reference active current in the fundamental reference. In the proposed control scheme, the role of the dclink voltage controller is not only to ensure a proper operation of the APF but also to help the APF deal with load variations.
In this paper, even though the load current measurement is not used, the load changes can be detected indirectly through dc link voltage variations.

Hence, by detecting and regulating the dc-link voltage, the shunt APF can recognize and respond against load variations without the load current measurement.

\section{B. Supply Current Control Loop}

The reference active current is the output of the dclink voltage control loop, while the reference reactive current is simply set to be zero. Consequently, the reactive power caused by loads can be fully compensated by the APF, and also unity power factor condition is achieved at the supply side.

\section{Control Signal Computation for the Four- Switch APF}

The four-switch APF is introduced by replacing the traditional three-phase VSI with the FSTPI with-out degrading the performance of the proposed control strategy. The FSTPI is composed of four power switching devices and two split capacitors [17], [18].

\section{Supply voltage PLL}

In practical distribution network, supply voltage is regularly not pure sinusoidal but contains harmonic components, which may affect to the accuracy of the PLL. To overcome this problem, band pass filter tuned at the fundamental frequency of the supply voltage is implemented to reject all of the harmonic components contained in supply voltage, and its output contains only the fundamental component which is used as the input of the PLL block as shown in fig 3.

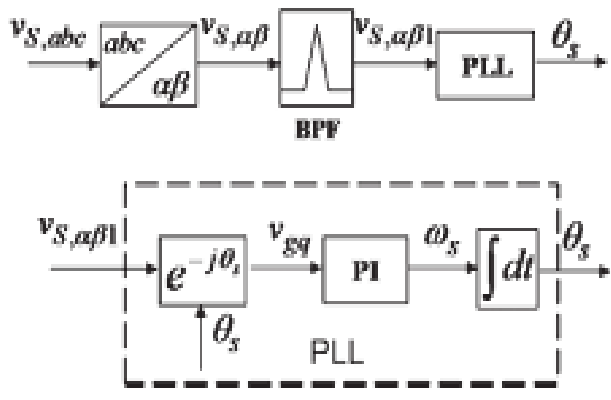

Fig. 4. Block diagram of improved PLL

\section{E. Current Controller Design}

In order to design the gains for the PI-VPI controller and to investigate the effect of these gains on the control performance, the closed-loop transfer function of the PI-VPI current controller is analyzed. By selecting the resonant gain as $K r h=K p h R f / L f$ and $K i 1=K p 1 R f / L f$, the closed loop 
transfer function of the PI-VPI controller. The $K p h$ and $K p 1$ are the only gains that need to be tuned. In fact, $K p 1$ is the integrator gain of the PI controller that does not affect the harmonic compensation performance of the VPI controller. Thus, for the sake of simplification, $K p 1$ is kept constant, and $K p h$ is changed to determine the control performance of the VPI controller. At selected resonant frequencies, the VPI controller provides a unity gain and zero phase-shift, regardless of the value of $K p h$. Moreover, the narrowest bandwidth is achieved with $K p h=0.5$, which indicates that the VPI controller is more selective and obtain better steady-state performance if $K p h$ is a smaller value. In harmonic compensation application, the steady-state performance is regarded as the most critical index; thus it prefers to choose $K p h$ to be a small value $(K p h<1)$.

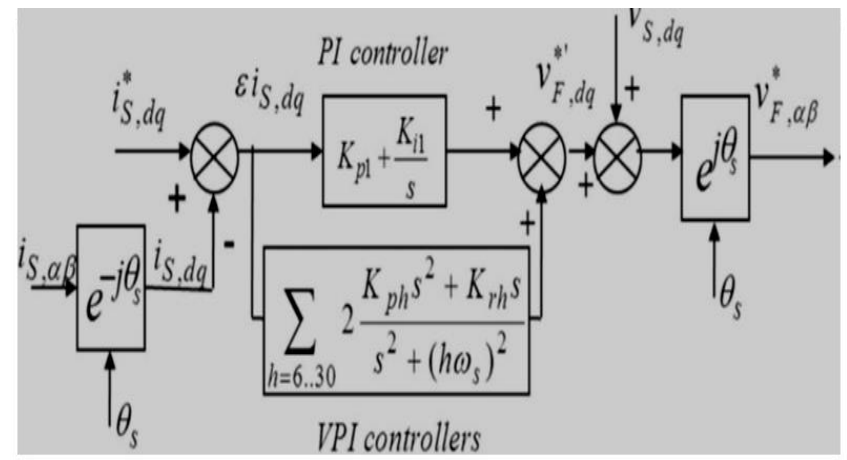

Fig. 5. Block diagram of current controllers

\section{SIMULATION RESULTS}

The system of Fig. 1 has been simulated using each one of the previously described current control techniques for the shunt active power filter. The controllers include the implementation of all the aforementioned refinements, so that the achieved performance is, as realistically as possible, at its best level. The figures from 5.1 to 5.5 shows the simulation results of voltage, current, real power, reactive power and Total Harmonic Distortion (THD) after compensation by Shunt active power filter.

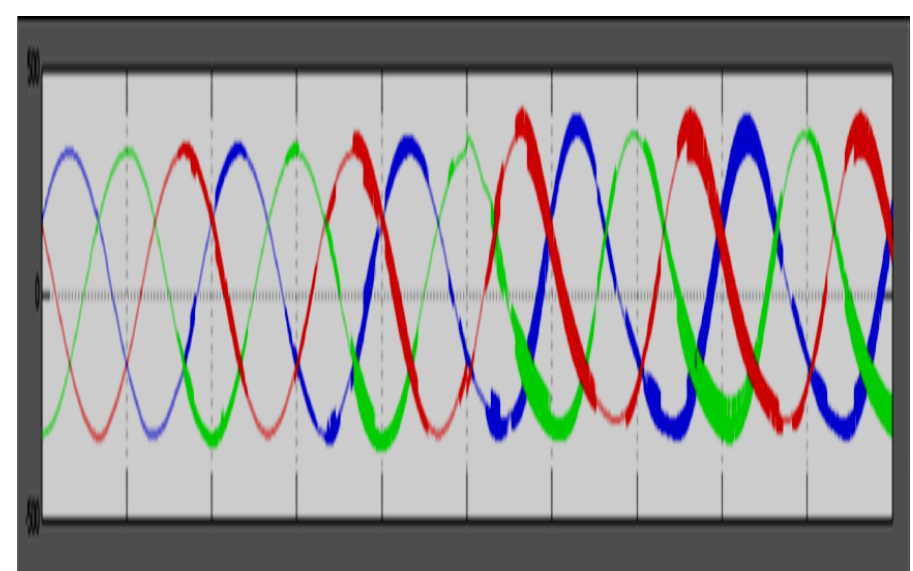

Fig. 6. Load voltage after compensation

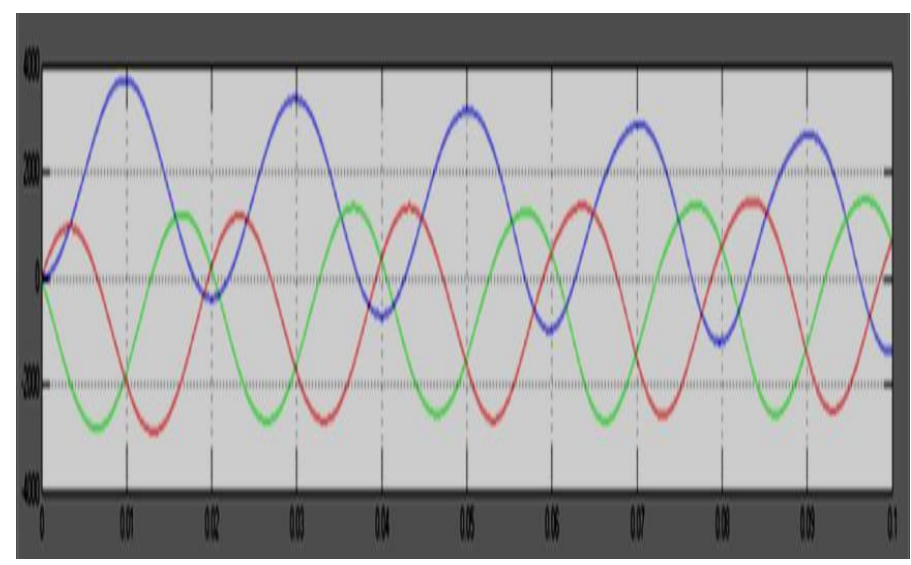

Fig. 7. Load current after compensation

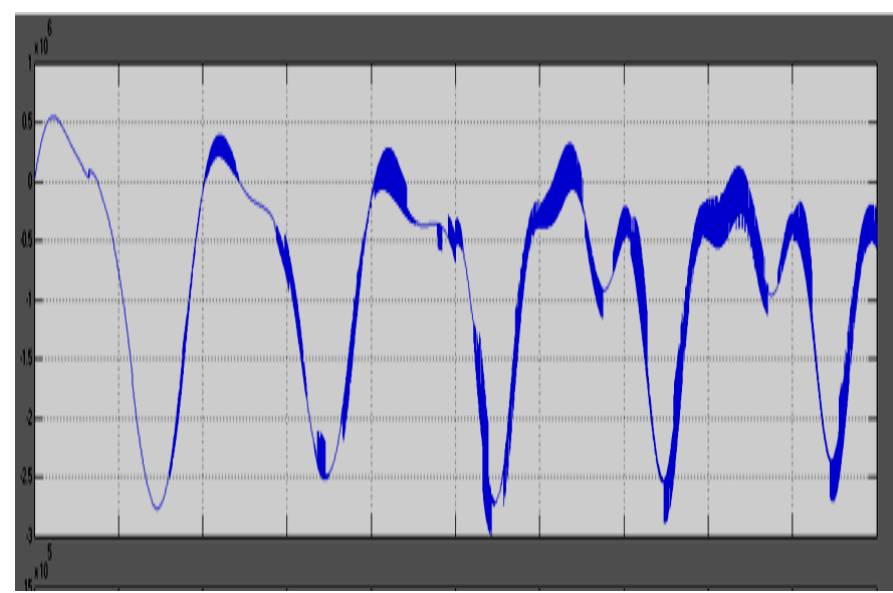

Fig. 8. Real power after compensation 


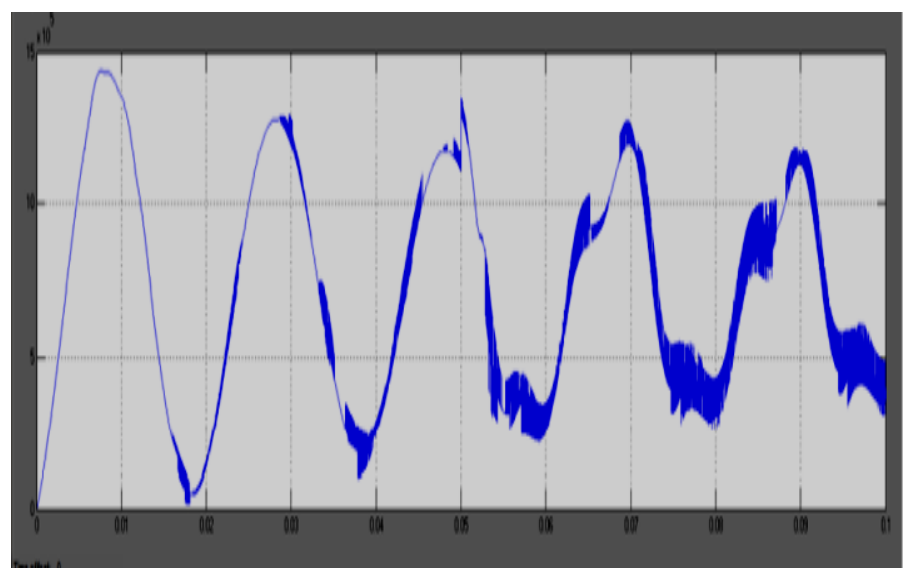

Fig. 9. Reactive power after compensation

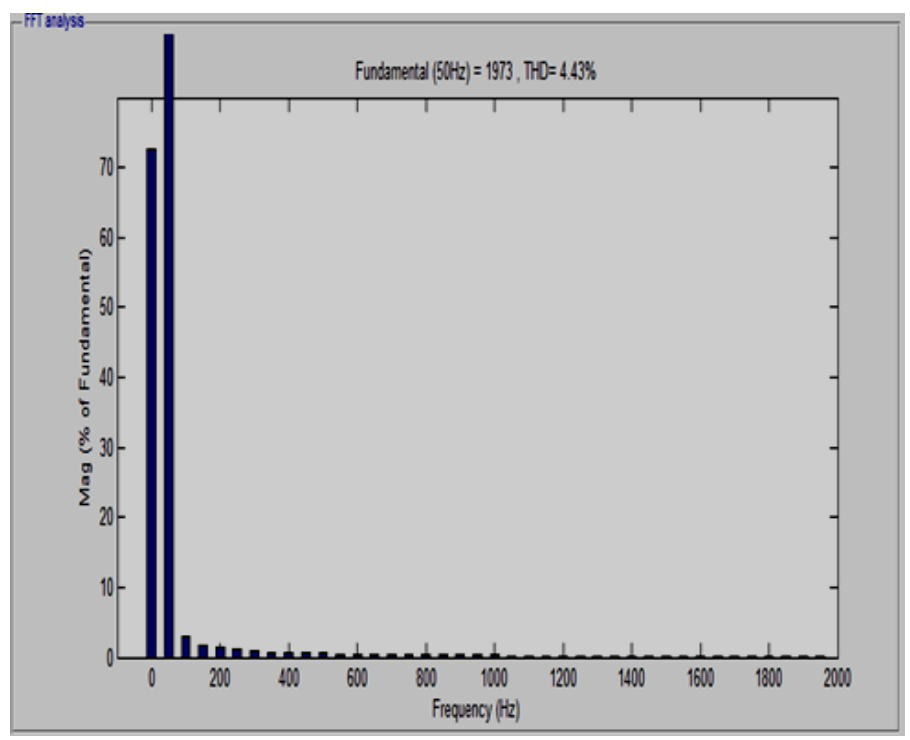

Fig. 10. FFT Analysis

\section{CONCLUSION}

In this paper, an advanced three-phase shunt APF was proposed for compensating various power quality issues. The proposed control strategy presented good steady-state performance with nonlinear RL and RLC loads as well as good dynamic response against load variations. The supply current, real and reactive power is almost perfect sinusoidal and in-phase with the supply voltage even under the distorted voltage condition using MATLAB simulation. The absence of harmonic detector results in faster transient responses. Moreover, we also confirmed that the FSTPI can be used to implement the APF without any degradation in the APF performance. The THD factor of the supply current was reduced to less than $5 \%$.

\section{REFERENCE}

[1]. H. Akagi, E. H. Watanabe, and M. Aredes, (2007) Instantaneous Power Theory and Applications to Power Conditioning, M.E.El-Hawari,Ed.New York.

[2]. S. Buso, L. Malesani, and P. Mattavelli, (1998) "Comparison of current control techniques for active filters applications," IEEE Trans. Ind. Electron.,vol. 45 , no. 5 , pp. $722-729$.

[3]. S. Rahmani, N. Mendalek, and K. Al-Haddad, (2010)"Experimental design of a nonlinear control technique for three-phase shunt active power filter," IEEE Trans. Ind. Electron., vol. 57, no. 10, pp. 3364 3375 .

[4]. H. Hu, W. Shi, Y. Lu, and Y. Xing, (2012) "Design considerations for DSP controlled $400 \mathrm{~Hz}$ shunt active power filter in an aircraft power system," IEEE Trans. Ind. Electron., vol. 59, no. 9, pp. 3624-3634.

[5]. Z. Chen, Y. Luo, and M. Chen, (2012) "Control and performance of a cascaded shunt active power filter for aircraft electric power system," IEEE Trans. Ind. Electron., vol. 59, no. 9, pp. 3614-3623.

[6]. L. Asiminoaei, F. Blaabjerg, and S. Hansen, (2007) "Detection is key-Harmonic detection methods for active power filter applications," IEEE Ind. Appl. Mag., vol. 13, no. 4, pp. 22-33.

[7]. R. R. Pereira, C. H. da Silva, L. E. B. da Silva, G. Lambert-Torres, and J. O. P. Pinto, (2011) "New strategies for application of adaptive filters in active power filters," IEEE Trans. Ind. Appl., vol. 47, no. 3, pp. 1136-1141.

[8]. Bhattacharya and C. Chakraborty, (2011) "A shunt active power filter with enhanced performance using ANN-based predictive and adaptive controllers," IEEE Trans. Ind. Electron., vol. 58, no. 2, pp. 421428.

[9]. F. A. S. Neves, H. E. P. de Souza, M. C. Cavalcanti, F. Bradaschia, and E. J. Bueno, (2012) "Digital filters for fast harmonic sequence component separation of unbalanced and distorted three-phase signals," IEEE Trans. Ind. Electron., vol. 59, no. 10, pp. 3847-3859.

[10]. R. I. Bojoi, G. Griva, V. Bostan, M. Guerriero, F. Farina, and F. Profumo, (2005) "Current control strategy for power conditioners using sinusoidal signal integrators in synchronous 
reference frame," IEEE Trans. Power Electron., vol. 20 , no. 6, pp. 1402-1412.

[11]. C. Lascu, L. Asiminoaei, I. Boldea, and F. Blaabjerg, (2009) "Frequency response analysis of current controllers for selective harmonic compensation in active power filters," IEEE Trans. Ind. Electron., vol. 56, no. 2, pp. 337-347.

[12]. L. Limongi, R. Bojoi, G. Griva, and A. Tenconi, (2009) "Digital current-control schemes," IEEE Ind. Electron. Mag., vol. 3, no. 1, pp. 20-31.

[13]. C. Lascu, L. Asiminoaei, I. Boldea, and F. Blaabjerg, (2007) "High performance current controller for selective harmonic compensation in active powerfilters," IEEE Trans. Power Electron. vol. 22 , no. 5, pp. 1826-1835.

[14]. M. Singh, V. Khadkikar, and A. Chandra, (2011) "Grid synchronization with harmonics and reactive power compensation capability of a permanent magnet synchronous generator-based variable speed wind energy conversion system," IET Power Electron., vol. 4, no. 1, pp. 122-130.

[15]. F. Blaabjerg, D. Neacsu, and J. K. Pedersen, (1999) "Adaptive SVM to compensate DC-Link voltage ripple for four-switch three-phase," IEEE Trans. Power Electron., vol. 14, no. 4, pp. 743-752.

[16]. M. B. de R. Corrêa, C. B. Jacobina, E. R. C. da Silva, and A. M. N. Lima, (2006) "A general PWM strategy for four-switch three phase inverter," IEEE Trans. Power Electron., vol. 21, no. 6, pp. $1618-1627$.

[17]. Recommended Practice for Harmonic Control in Electric Power Systems, IEEE Std. 5191992, 1992.

[18]. Limits for Harmonic Current Emission, IEC 61000-3-2, 2001. 